\title{
Fear of stigma, beliefs, and knowledge about HIV are barriers to early access to HIV testing and disclosure for perinatally infected children and adolescents in rural communities in South Africa
}

\author{
Sphiwe Madiba** iD and Mathildah Mokgatle \\ ${ }^{a}$ Department of Environmental and Occupational Health, School of Public Health, Sefako Makgatho Health Sciences University, Pretoria, South Africa \\ ${ }^{b}$ Department of Biostatistics, School of Public Health, Sefako Makgatho Health Sciences University, Pretoria, South Africa \\ *Corresponding author, email: sphiwe_madiba@embanet.com

\begin{abstract}
Background: The majority of HIV-infected children in resource-limited countries are not aware of their HIV status because of the various reasons responsible for the delay in seeking HIV testing for children. The aim of the study was to determine the prevalence and barriers to testing and disclosing the HIV status of children aged between 5 and 18 years.

Methods: This was a cross-sectional survey involving 405 caregivers of HIV perinatally infected children receiving anti-retroviral treatment (ART) in primary health care facilities in a rural district of Mpumalanga province in South Africa.

Results: The prevalence of disclosure was $27 \%$, and disclosure was done to promote adherence (26\%) or because it was the child's right to know his/her status (43\%). Children's age was significantly associated with disclosure (AOR $=2.81, p<0.000, \mathrm{Cl}$ 1.64-4.81). Concerns that children were too young and would not understand the implications of HIV diagnosis (74.5\%) or would not keep the diagnosis secret (7\%) were reasons for non-disclosure. Over half of the caregivers intended to disclose status when the child was aged between 12 and 15 years. In response to children's questions about medication, caregivers substituted HIV with other less stigmatising conditions (32\%).

Conclusion: The prevalence of disclosure was low and delayed till the child was above 10 years of age. The main barrier to disclosure was fear of stigma, or fears of the child telling others about their HIV status with consequences of stigma. The need for guidelines to provide caregivers with disclosure skills, to overcome the barriers that prevent disclosure, is crucial.
\end{abstract}

Keywords: caregivers, disclosure, HIV testing, perinatal infected children, rural setting

\section{Introduction}

The wide availability of first-line anti-retroviral treatment (ART) for HIV-infected children does not ensure timely access for children and adolescents in limited resource settings. ${ }^{1}$ In South Africa, less than half of the children in need of ART have access. ${ }^{2}$ Some of the structural barriers for HIV testing include limited availability of community-based HIV counselling and testing services for children, and difficulties in identifying HIV-infected infants. ${ }^{3,4}$ Thus, for many children and adolescents, HIV diagnosis occurs in late childhood, following many years of ill-health., ${ }^{3,5,6}$ However, there are also personal risk factors for late diagnosis of perinatally infected children and adolescents. Caregivers' lack of awareness of HIV symptoms, and misperceptions of paediatric HIV disease and treatment discourage caregivers from seeking treatment care and support for children. ${ }^{1,7}$ In addition, HIVrelated stigma has been shown to determine caregivers' decision to test their children more than the benefits of an HIV test. ${ }^{8,9}$

Data on barriers to ART access for HIV-infected children and adolescents are limited because existing studies on HIV counselling and testing for children are largely among children already enrolled in HIV programmes.? For this reason, disclosure of HIV diagnosis to perinatally infected children remains understudied in resource-limited settings. ${ }^{10,11}$ Still, available data show that the majority of HIV-infected children in resource-limited countries are not aware of their HIV status, primarily for the same reasons that determine the delay in seeking HIV testing for children. ${ }^{10,12}$ The low prevalence of disclosure in these settings suggests that caregivers face more barriers to disclosure, perhaps due to higher prevalence of HIV-related stigma. Disclosure is delayed because of concerns that children would not keep the diagnosis secret and caregivers fear subsequent stigmatisation of the family. ${ }^{10,13}$

Besides the fear of stigma, there are other factors that influence how and when caregivers decide to disclose to children perinatally infected with HIV. Although caregivers recognise that disclosure to children is beneficial and significant to the longterm management and prevention of HIV, they weigh this against feared risks of disclosure. ${ }^{12}$ The concern for public health is that the disclosure process in adolescents is poorly documented in southern Africa, and it is not well established what factors shape disclosure or non-disclosure to children and adolescents, particularly in rural settings. ${ }^{14,15}$ Thus, we first determined the proportion of children and adolescents who were informed about their HIV diagnosis. We further determined caregivers' beliefs and fears regarding disclosure and non-disclosure of HIV status to infected children in their care. It is imperative that factors that hinder disclosure are identified to develop disclosure interventions that are specific for the local context of caregivers.

\section{Materials and methods}

This was a cross-sectional survey involving 406 caregivers of perinatally HIV-infected children and adolescents aged between 5 and 18 years on ART. This study is part of a cross-sectional survey, which investigated the provision of, and utilisation of, HIV 
Table 1: Demographic characteristics of primary caregivers of HIV infected children

\begin{tabular}{|c|c|c|}
\hline Factor & Frequency & Percentage \\
\hline \multicolumn{3}{|l|}{ Relationship to the child } \\
\hline Biological mother & 158 & 38.9 \\
\hline Biological father & 11 & 2.7 \\
\hline Grandparents & 122 & 30.1 \\
\hline Other relatives" & 115 & 28.3 \\
\hline \multicolumn{3}{|l|}{ Gender of caregiver } \\
\hline Female & 372 & 91.6 \\
\hline Male & 34 & 8.4 \\
\hline \multicolumn{3}{|l|}{ Age of caregiver } \\
\hline Less than 40 years & 198 & 49.0 \\
\hline Over 40 years & 206 & 51.0 \\
\hline \multicolumn{3}{|l|}{ Marital status of caregiver } \\
\hline Never married & 216 & 53.2 \\
\hline Ever married & 190 & 46.8 \\
\hline \multicolumn{3}{|l|}{ Employment status } \\
\hline Unemployed & 280 & 69.0 \\
\hline Employed & 73 & 18.0 \\
\hline Pensioner & 53 & 13.1 \\
\hline \multicolumn{3}{|l|}{ Formal educational } \\
\hline None & 60 & 14.8 \\
\hline Primary & 98 & 24.1 \\
\hline Secondary & 163 & 40.2 \\
\hline Completed 12 th grade & 69 & 17 \\
\hline Tertiary & 16 & 3.9 \\
\hline \multicolumn{3}{|l|}{ Source of income } \\
\hline Child support grant & 282 & 70.7 \\
\hline Old-age pension grant & 78 & 19.6 \\
\hline Other sources & 39 & 9.8 \\
\hline \multicolumn{3}{|l|}{ Caregiver ever tested } \\
\hline No & 38 & 9.4 \\
\hline Yes & 368 & 90.6 \\
\hline \multicolumn{3}{|l|}{ Caregiver HIV status } \\
\hline Negative & 174 & 42.9 \\
\hline Positive & 194 & 47.8 \\
\hline Unknown & 38 & 9.4 \\
\hline
\end{tabular}

*Other relatives includes older sibling, uncles, and aunts.

testing and counselling for perinatally infected children, and the burden of HIV disease in primary health care (PHC) facilities in a rural district in Mpumalanga province, South Africa. The survey was conducted between June and September 2013 in two community hospitals and 34 PHC facilities. The health facilities were located in three sub-districts of Mpumalanga province; one of the districts was urban and the other two were rural. The majority of the health facilities were located in the rural subdistricts. The sub-districts are characterised by unemployment and poverty but have adequate access to PHC services, as most people walk to the local PHC facility. The survey is fully reported elsewhere; ${ }^{16}$ this paper reports on disclosure of HIV status to children and adolescents infected with HIV.

\section{Data collection}

A convenience sample of caregivers was selected to participate in the study during the routine visits of their children to the PHC facility. Caregivers were included if their children were receiving ART in the selected facilities. A primary caregiver was defined as an adult who lives in the same house as the child, is responsible for the day-to-day care of the child, and has knowledge about the child's HIV diagnosis, ART treatment and care. Consenting caregivers were interviewed privately and in the absence of their children, to maintain confidentiality and prevent inadvertent disclosure to children. A structured interviewer-administered pre-tested questionnaire, developed in English and translated into IsiZulu and Sepedi (local languages), was used to elicit caregiver and children's demographic characteristics. The first author is proficient in Isizulu and Sepedi and verified that the translation was consistent with the English version. For caregivers who reported disclosure, the tool captured information on children's age at HIV diagnosis, age at the start of ART, age at disclosure, and person who disclosed. For caregivers who had not disclosed, the tool captured information on their intentions to disclose, the preferred age when they would disclose, and the preferred person to disclose to the child. The tool also contained open-ended questions on the reasons for disclosure or nondisclosure. Trained field workers conducted the interviews under the supervision of one of the authors (MM).

\section{Ethical considerations}

Ethical clearance for this study was obtained from the Research and Ethics Committee of the University of Limpopo, Medunsa Campus (MREC/H/168/2012: IR). Permission to conduct the study was granted by the Research Committee of the Mpumalanga Provincial Department of Health. Written and verbal informed consent were obtained from the caregivers before questionnaires were administered; caregivers were also informed that participation was voluntary and assured of the confidentiality of their responses.

\section{Data analysis}

Statistical analyses were performed using STATA version $13.0^{\circledR}$ (StataCorp, College Station, TX, USA). Pearson chi-square tests were used to assess whether there were any associations between caregiver and child categorical variables, and the outcome variable (disclosure to child). Student's t-tests were used to compute the mean age of the children with disclosed information and with non-disclosure. Univariate and multivariate analyses using logistic regression were performed to determine which categorical variables were significantly associated with disclosure. All variables with $p \leq 0.005$ in the univariate analysis were included in the multivariable logistic regression model using a forward step-wise approach. Results are expressed as odds ratios (ORs) with $95 \%$ confidence intervals (Cls) and $p$-values. For all analyses, a $p$-value $\leq 0.05$ was considered significant.

\section{Results}

\section{Demographic characteristics of caregivers}

The sample consisted of 406 caregivers of perinatally infected children aged between 5 and 17 years. The majority of caregivers were female ( $n=372,91.6 \%)$; the mean age was 44.2 years (range $17-89$ years). Most ( $n=158,38.9 \%)$ were the biological mothers, $122(30.1 \%)$ were grandparents, and 138 (30.7\%) were other relatives. Ninety-eight (24.1\%) had primary education, 280 (69\%) 
Table 2: Demographic and clinical characteristics of HIV infected children by disclosure status

\begin{tabular}{|c|c|c|c|}
\hline \multirow[t]{2}{*}{ Factor } & \multicolumn{2}{|c|}{ Disclosure status } & \multirow[b]{2}{*}{$p$-value } \\
\hline & $\begin{array}{l}\text { Not disclosed } \\
\quad(n=294)\end{array}$ & $\begin{array}{c}\text { Disclosed } \\
(n=111)\end{array}$ & \\
\hline Current age & & & 0.000 \\
\hline $5-9$ years & $168(57.1)$ & $30(27.0)$ & \\
\hline $10-17$ years & $126(42.9)$ & $81(73.0)$ & \\
\hline Sex of child & & & 0.569 \\
\hline Girl & $139(47.3)$ & $56(50.5)$ & \\
\hline Boy & $155(52.7)$ & $55(49.6)$ & \\
\hline $\begin{array}{l}\text { Age at HIV diag- } \\
\text { nosis }\end{array}$ & & & 0.000 \\
\hline $0-5$ years & $170(59.7)$ & $40(37.4)$ & \\
\hline $6-10$ years & $97(34.0)$ & $43(40.2)$ & \\
\hline $11-16$ years & $18(6.3)$ & $24(22.4)$ & \\
\hline $\begin{array}{l}\text { Age at ART initi- } \\
\text { ation }\end{array}$ & & & 0.000 \\
\hline $0-5$ years & $147(52.1)$ & $37(34.3)$ & \\
\hline $6-10$ years & $117(41.5)$ & $44(40.7)$ & \\
\hline $11-16$ years & $18(6.4)$ & $27(25.0)$ & \\
\hline ART duration & & & 0.146 \\
\hline $0-5$ years & $215(75.4)$ & $72(66.1)$ & \\
\hline $6-10$ years & $63(22.1)$ & $32(29.4)$ & \\
\hline $11-16$ years & $7(2.5)$ & $5(4.6)$ & \\
\hline $\begin{array}{l}\text { Reasons for HIV } \\
\text { testing }\end{array}$ & & & 0.759 \\
\hline Child was ill & $229(77.9)$ & $90(81.8)$ & \\
\hline Illness of parents & $29(9.9)$ & $10(9.1)$ & \\
\hline Death of mother & $18(6.1)$ & $4(3.6)$ & \\
\hline Other & $18(6.1)$ & $6(5.5)$ & \\
\hline Hospitalisation & & & 0.927 \\
\hline No & $145(49.5)$ & $55(50.0)$ & \\
\hline Yes & $148(50.5)$ & $55(50.0)$ & \\
\hline Orphan status & & & 0.171 \\
\hline Orphan & $126(42.9)$ & $56(50.5)$ & \\
\hline Non-orphan & $168(57.1)$ & 55 (49.6) & \\
\hline
\end{tabular}

were unemployed and 53 (13.1\%) were elderly pensioners. The source of income for 282 (70.7\%) was the child support grant and for $78(19.2 \%)$ the old-age pension grant. Almost half $(n=194$, $47.8 \%$ ) of the caregivers were HIV positive (Table 1).

\section{Demographic and clinical characteristics of children}

Table 2 presents the characteristics of 406 children. Over half ( $n=208$ (51.3\%) were aged between 10 and 17 years, 198 (48.8\%) were between 5 and 9 years, and the mean age was 9.6 years ( $S D=3.05$, range $5-17$ years). Almost half ( $n=183,45.2 \%)$ of the children had lost their mothers (maternal orphans), 123 (31.5\%) had lost their fathers (paternal orphans), and 73 (39.9\%) had lost both parents (double orphans). The majority of children ( $n=319$, $78.8 \%$ ) suffered from recurrent and chronic illnesses when they initially tested for HIV, 39 (9.6\%) were tested because one or both parents were ill, and 23 (5.7\%) were tested after the death of the mother. Half ( $n=203,50.2 \%$ ) of the children were admitted to hospital prior to HIV testing and start of ART.
Children had been diagnosed as HIV infected at a mean age of 4.8 years ( $\mathrm{SD}=3.6$, range $0-16$ years). Slightly over half $(n=210$, $53.4 \%)$ were diagnosed between 0 and 5 years, 140 (35.6\%) between 6 and 10 years, and $43(10.4 \%)$ were older than 10 years.

At the time of the interview, all the children were on ART with a mean duration of ART use of 4 years, $184(47.1 \%)$ were initiated on ART between 0 and 5 years, $162(41.4 \%)$ between 6 and 10 years, and $45(11.5 \%)$ above 10 years. Over half $(n=207$, $52.6 \%)$ were older than five years when they were initiated on ART. The mean age at the time of ART initiation was 5.6 years ( $\mathrm{SD}=3.4$, range $0-16$ years).

\section{Disclosure status}

The majority ( $n=308,75.9 \%$ ) of caregivers believed that disclosure to children is important and that it should be done, yet less than a third ( $n=111,27.4 \%)$ of the children were informed about their HIV diagnosis, 61 (61\%) had been told their diagnoses at $10-16$ years and $39(39 \%)$ at $5-9$ years. The mean age at disclosure was 9.84 years ( $S D=2.9$ years, range $5-16$ years). The proportion of children who knew their status was greater among older children compared with young children.

For over a third ( $n=31,31 \%)$ of the children, disclosure was made by the biological parents, $27(27 \%)$ by health professionals, $22(22 \%)$ by grandparents, and $20(20 \%)$ by other relatives.

Most caregivers disclosed because they believed that the child has a right to know the status ( $n=32,43.2 \%)$, to improve adherence to treatment $(n=26,35.1 \%)$, to respond to the child's questions about medication ( $n=9,12.1 \%$ ), the child was old enough to understand HIV ( $n=4,5.4 \%)$, and to prevent the child from infecting others $(n=3,4.1 \%)$ (Table 3 ).

\section{Non-disclosure and intention to disclose}

Table 4 presents the reasons for not disclosing the HIV status to the children. The main reason was concern that the child was too young ( $n=153 ; 52 \%$ ), the child would tell others and the family might be stigmatised ( $n=21,7.1 \%$ ), the child would experience negative reactions to disclosure $(n=24 ; 8.2 \%)$, the child would not understand what HIV is all about $(n=66 ; 22.4 \%)$, the child would harm him/herself and commit suicide ( $n=10 ; 3.45 \%)$, the child would think he/she was different from others and self-stigmatise $(n=10 ; 3.4 \%)$, and caregiver lack of disclosure skills $(n=10 ; 3.4 \%)$.

Non-disclosed caregivers were asked about what they told their children about taking medication and their illness: 115 (43.9\%) said the child did not ask about the illness or medication, 86 (32.8\%) substituted HIV with other less stigmatising conditions, 26 (19.3\%) stated that they changed the discussion, 35 (13.4\%) said nothing to the child about his/her medication.

Almost all ( $n=277 ; 94.9 \%)$ thought that disclosure should be made after 10 years, but the mean preferred age of disclosure was 13.5 years ( $S D=2.9$; range $6-21$ years). Over half $(n=154$; $52.7 \%$ ) thought that disclosure should be made between 10 and 14 years of age, 121 (41.4\%) said between 15 and 20 years of age, and $15(5.1 \%)$ felt that disclosure should be made before 10 years of age.

The majority ( $n=49 ; 46.4 \%$ ) of caregivers preferred to disclose the HIV status to children themselves, 7 (2.2\%) thought that the caregiver and health provider should disclose, and 62 (19.8\%) thought that the health providers should disclose (Table 4). 
Table 3: Disclosure status of children and caregiver reasons for disclosure

\begin{tabular}{|c|c|c|}
\hline Variables & Frequency & Percentage \\
\hline \multicolumn{3}{|l|}{ Disclosure status $(n=405)$} \\
\hline Disclosed & 111 & 27.4 \\
\hline Not disclosed & 294 & 72.6 \\
\hline \multicolumn{3}{|l|}{ Age at HIV disclosure $(n=100)$} \\
\hline $5-9$ years & 39 & 39.0 \\
\hline $10-16$ years & 61 & 61.0 \\
\hline \multicolumn{3}{|l|}{$\begin{array}{l}\text { Person who disclosed HIV status to child } \\
(n=100)\end{array}$} \\
\hline Parents & 31 & 31 \\
\hline Healthcare workers & 27 & 27 \\
\hline Other relatives & 42 & 42 \\
\hline \multicolumn{3}{|l|}{ Caregivers' reasons for disclosure $(n=74)$} \\
\hline To improve adherence to treatment & 26 & 35.1 \\
\hline To prevent infecting others & 3 & 4.0 \\
\hline $\begin{array}{l}\text { The child was asking questions about } \\
\text { taking medication }\end{array}$ & 9 & 12.2 \\
\hline $\begin{array}{l}\text { The child was old enough to understand } \\
\text { HIV }\end{array}$ & 4 & 5.4 \\
\hline It's the child's right to know his/her status & 32 & 43.2 \\
\hline
\end{tabular}

Table 4: Caregiver-reported barriers to disclosure and intentions to disclose

\begin{tabular}{|c|c|c|}
\hline Factor & Number & Percentage \\
\hline \multicolumn{3}{|l|}{$\begin{array}{l}\text { Barriers preventing disclosure to children } \\
(n=294)\end{array}$} \\
\hline Child would harm him/herself & 10 & 3.4 \\
\hline Fear of negative reactions to disclosure & 24 & 8.2 \\
\hline Child would tell others & 21 & 7.1 \\
\hline Fear of discrimination & 10 & 3.4 \\
\hline Child does not understand HIV & 66 & 22.4 \\
\hline Child is too young & 153 & 52.0 \\
\hline Lack skills to disclose & 10 & 3.4 \\
\hline \multicolumn{3}{|l|}{$\begin{array}{l}\text { Communicating with children without disclo- } \\
\text { sure }(n=262)\end{array}$} \\
\hline $\begin{array}{l}\text { Child does not ask about his/her illness or } \\
\text { medication }\end{array}$ & 115 & 43.9 \\
\hline Caregiver says nothing about the illness & 35 & 13.4 \\
\hline Substitute HIV with other diseases & 86 & 32.8 \\
\hline Change the discussion & 26 & 9.9 \\
\hline \multicolumn{3}{|l|}{ Preferred age at disclosure $(n=292)$} \\
\hline$<10$ years & 15 & 5.1 \\
\hline $10-14$ years & 154 & 52.7 \\
\hline $15-20$ years & 121 & 41.4 \\
\hline$>20$ years & 2 & 0.7 \\
\hline \multicolumn{3}{|l|}{$\begin{array}{l}\text { Preferred person to disclose HIV to child } \\
(n=314)\end{array}$} \\
\hline Caregiver & 245 & 78.0 \\
\hline Caregiver and health provider & 7 & 2.2 \\
\hline Health provider & 62 & 19.8 \\
\hline
\end{tabular}

\section{Factors associated with disclosure}

Child age, age at diagnosis, and age at ART initiation were associated with disclosure status of children. Children diagnosed at age 11-16 years were 5.6 times more likely to be disclosed to than those aged $0-5$ years $(\mathrm{OR}=5.6, p<0.000 ; \mathrm{Cl}=2.80-11.42)$, children aged 10-17 years were 3.6 times more likely to be disclosed to than those aged $5-9$ years $(\mathrm{OR}=3.6, p<0.000, \mathrm{Cl}=$ 2.23-5.80). Children who started ART at age 11-15 years were 5.9 times more likely to be disclosed to than those aged $0-5$ years $(\mathrm{OR}=5.9, p<0.000, \mathrm{Cl}:=2.96-11.9)$.

Caregivers who had primary education were three times more likely to disclose than those who did not have any formal education ( $\mathrm{OR}=3.0, p=0.012, \mathrm{Cl}=1.27-7.08)$.

In multivariate analyses, only children's age remained significantly associated with disclosure $(\mathrm{OR}=2.81, p<0.000, \mathrm{Cl} 1.64-4.81)$ (Table 5).

\section{Discussion}

This study investigated the prevalence and barriers to test and disclose HIV status to children in rural communities in South Africa. Almost half (45.2\%) of the children were orphans and were accompanied to the health facilities for ART follow-up by grandparents, aunts, uncles, and older siblings. All the children were receiving ART at the time of the survey with a mean duration of ART use of four years. Consistent with other studies, children were chronically ill from recurrent infections when caregivers sought HIV testing. ${ }^{1,17,18}$ A study conducted in Uganda reported that lack of HIV-specific perinatal care, orphan-hood, caregiver financial constraints, unawareness of HIV symptoms, and fear of stigma were risk factors for late disease stage at presentation among perinatal infected children. ${ }^{1}$ In the current study, half of the children were orphans and the majority were cared for by grandparents who were pensioners with low literacy levels and poor socio-economic status. The age at which children were tested for HIV varied greatly, but almost half were older than five years when they were tested and diagnosed with HIV.

The prevalence of disclosure to children was low (27.4\%) and similar to studies conducted elsewhere, ${ }^{10,19,20}$ but lower than previous findings in South Africa. Mahloko and Madiba ${ }^{21}$ reported a prevalence of $40 \%$ in an urban setting. Disclosure was low, despite all the children receiving ART for a mean duration of four years and most caregivers (75.9\%) believing that children have a right to know their status. Similarly, John-Stewart and colleagues found that disclosure remained low even with repeated clinic visits providing opportunities for disclosure. ${ }^{10}$ This suggests that caregivers in limited-resourced settings face more barriers to disclose due to higher prevalence of HIV-related stigma. We found that one of the barriers to disclose was a caregiver's concerns that the child would not keep the diagnosis secret and feared that the family would be stigmatised. These findings have been documented in other studies. ${ }^{10,20-23}$

Disclosure to children was delayed, the mean age at disclosure was 9.8 years, and for the majority of children (61\%) disclosure occurred between 10 and 16 years. The mean age at disclosure is consistent with an earlier study conducted in South Africa. ${ }^{24}$ Findings from other studies had suggested that low levels of disclosure are the result of caregivers disclosing to older children as they believed that they can understand an HIV diagnosis. 19,21,25 
Table 5: Multivariate logistic regression of HIV disclosure to child

\begin{tabular}{lccccc}
\hline Factor & Odds ratio & Std. error & $\mathbf{z}$ & $\boldsymbol{p}>\mathbf{z}$ & {$[95 \% \mathrm{CI}]$} \\
\hline Child age & 2.82 & 0.775 & 3.77 & 0.000 & $1.64-4.83$ \\
$\begin{array}{l}\text { Age at HIV } \\
\text { diagnosis }\end{array}$ & 1.57 & 0.413 & 1.71 & 0.087 & $0.94-2.63$ \\
$\begin{array}{l}\text { ART start age } \\
\begin{array}{l}\text { Caregiver } \\
\text { educational }\end{array}\end{array}$ & 1.18 & 0.320 & 0.61 & 0.541 & $0.69-2.01$ \\
level & 1.16 & 0.139 & 1.24 & 0.216 & $0.92-1.47$ \\
\hline
\end{tabular}

This was not the case in the current study, since $51 \%$ of the children were above 10 years old and yet the prevalence of disclosure remained low, and only $60 \%$ of the disclosed children were older than 10 years. Similarly, almost all caregivers thought that disclosure should be made after 10 years of age, and over half intended to disclose when the child was between 12 and 15 years. The mean preferred age of disclosure was 13.5 years, which was higher than that reported in other studies. ${ }^{13,20,22}$

We found that even though older age of the child was a determinant for disclosure in the logistic regression analysis, it was not the main reason disclosure occurred. Age on its own is not the main determinant for disclosure to perinatally infected children. There is evidence that caregivers in developing and developed countries do not agree on the most appropriate age for disclosure. This is also evident in the current study where we found that disclosure occurred between 10 and 16 years. The main reasons given for disclosure were to improve adherence to treatment (35\%) and belief that the child had a right to know his/ her status (43\%). For a small proportion of children (12\%), disclosure occurred in response to the child asking questions about why he/she was taking medication. These reasons have been reported in other studies. ${ }^{18,21,25-28}$ Consistent with other studies, ${ }^{10,21,28}$ most caregivers $(84.6 \%)$ disclosed the child's status to other people despite the low disclosure to children.

The most commonly cited reason for non-disclosure was the child's age; caregivers had concerns that the child was too young and would not understand an HIV diagnosis (74.5\%). These concerns also meant that because the children would not understand the implications of an HIV diagnosis, they would not be able to keep a secret. Hence, they deferred disclosure to an age when the child would understand the meaning of an HIV diagnosis. Fear that disclosure would have negative emotional consequences on the child and that the child would harm him/ herself by committing suicide were other child-related reasons for non-disclosure. Caregiver-related reasons for non-disclosure were lack of skills to disclose. This is consistent with the fact that some caregivers preferred disclosure to be conducted by healthcare workers (HCWs). These reasons are not different from reports in other studies. ${ }^{10,13,15,18,19,21,23,26}$

Despite concerns about not knowing how to disclose, most caregivers believed that the caregiver is the most appropriate person to disclose to children under their care. In the current study and others, disclosure for the majority of the children (73\%) was made by family members who are the primary caregivers of the children. ${ }^{20,21,25,27}$ In a recent study conducted in South Africa, healthcare workers also viewed disclosure to children as the responsibility of the caregivers. ${ }^{29}$ Even though caregivers desire to conduct the disclosure themselves, the role of the HCWs in disclosure to children should not be undermined. Literature shows that HIV disclosure for a number of children is done by the HCWs. ${ }^{26-28}$ In the current study, disclosure for about a third (27\%) of the children was conducted by HCWs. About $20 \%$ of caregivers expressed the need for support from HCWs to disclose to their children. Other studies found that caregivers believed that disclosure should be done by caregivers together with HCWs. ${ }^{21-23,26}$ It is important that caregivers are supported to overcome the barriers that prevent them from disclosing, and HCWs have a crucial role to play in preparing caregivers to carry out the disclosure..$^{22,23,29}$

Even though children's questions provided the caregivers with an opportunity to disclose, this did not often occur. We found that instead, in response to children's questions, caregivers substituted HIV with other less stigmatising conditions like tuberculosis (32\%), while others changed the discussion or ignored the child's questions (9.9\%). Similar findings where children were told that they had a disease other than HIV have been reported elsewhere. ${ }^{18}$ Almost half of the caregivers (43.9\%) reported that their children did not ask about their illness or medication and (13\%) did not say anything to the children with regard to their illness. ${ }^{30}$

As reported in other studies, ${ }^{10,20,21,30}$ we found associations between disclosure status and child demographic and clinical characteristics. Child age more than 10 years, ART start age more than 10 years, and disclosure age more than 10 years were independently associated with increased odds of disclosure. In multivariate analyses, only child's age remained significantly and independently associated with disclosure. It is important that the demographic characteristic of perinatally infected children, particularly the age, is taken into consideration by healthcare providers when planning disclosure interventions. In the current study setting, HIV diagnosis was also delayed to an older age, hence the association of age and disclosure. Healthcare providers should promote early testing of HIV-affected children to diagnose perinatally infected children early for effective management of their HIV disease.

\section{Conclusions}

The prevalence of disclosure was low and delayed to when the children were above 10 years of age. Almost all the caregivers who had not disclosed thought that disclosure should be made after 10 years of age, although the preferred mean age at disclosure was much higher than the mean age at disclosure observed in the study. Although child's age was the only factor associated with disclosure, it was not the main reason disclosure occurred; caregivers disclosed to promote adherence to medication and in the belief that the child has a right to know his/her status.

The main barrier to disclosure was fear of stigma and discrimination. Although the caregivers had concerns that the child was too young for disclosure, in essence, fears of the child telling others about his/her HIV status with consequences for stigma and discrimination for the family and the child dissuaded caregivers from disclosure. We also found that non-disclosed caregivers lacked the knowledge and skills to disclose but desired to conduct the disclosure themselves. The desire to be the ones to disclose, while they lacked the skills, resulted in postponement of the disclosure event. The need to develop guidelines to provide caregivers with HIV knowledge and disclosure skills to overcome the barriers that prevent them from disclosing remain crucial in the endeavours to increase disclosure to HIV-infected children and adolescents. 


\section{Limitations}

The study was cross-sectional and we could not establish how disclosure was conducted. We also depended on the caregivers to report on disclosure status because children were not interviewed, and therefore caregivers might have over-reported disclosure to children due to social desirability. Recall bias was mitigated by verifying the information provided by the caregiver using the child's medical records.

The strength of the study is that it was conducted with a sample that was representative of children seeking HIV care in primary health facilities, making the findings generalisable in similar settings.

Contributions - MM and SM contributed equally in the design and implementation of the study as well as analysis and interpretation of data. SM drafted the manuscript, and SM and MM finalised the writing of the manuscript and read and approved the final manuscript.

Conflict of interest - The authors declared no potential conflict of interest.

Funding - The study was funded by the University of Limpopo Research and development grant.

\section{ORCID}

\section{Sphiwe Madiba (D) http://orcid.org/0000-0002-3735-1248}

\section{References}

1. Boender TS, Sigaloff KC, Kayiwa J, et al. Barriers to initiation of pediatric HIV treatment in Uganda: A mixed-method study. AIDS Research and Treatment 2012;2012.

2. Davies M-A, Keiser O, Eley B, et al. Outcomes of the South African national antiretroviral treatment programme for children: the leDEA Southern Africa collaboration. S Afr Med J. 2009;99.

3. Ferrand RA, Bandason $T$, Musvaire $P$, et al. Causes of acute hospitalization in adolescence: burden and spectrum of HIV-related morbidity in a country with an early-onset and severe HIV epidemic: a prospective survey. PLoS Med 2010;7:e1000178. https://doi. org/10.1371/journal.pmed.1000178

4. Mutanga JN, Raymond J, Towle MS, et al. Institutionalizing providerinitiated HIV testing and counselling for children: an observational case study from zambia. PLoS ONE 2012;7:e29656. https://doi. org/10.1371/journal.pone.0029656

5. Ahmed S, Kim MH, Sugandhi $N$, et al. Beyond early infant diagnosis. AIDS 2013;27:S235-S245. https://doi.org/10.1097/ QAD.0000000000000099

6. Bandason T, Langhaug LF, Makamba M, et al. Burden of HIV among primary school children and feasibility of primary school-linked HIV testing in Harare, Zimbabwe: a mixed methods study. AIDS Care 2013;25:1520-6. https://doi.org/10.1080/09540121.2013.780120

7. Kimani-Murage $E$, Manderson L, Norris S, et al. "It's my secret": barriers to paediatric HIV treatment in a poor rural South African setting. AIDS Care 2013;25:744-47. https://doi.org/10.1080/09540121.2012.74886

8. Madiba S, Mokwena K, Mokgatle M. Characteristics and pre ART hospitalization of HIV-infected children at enrolment in a district hospital HIV clinic, Gauteng province, South Africa. Int J Recent Sci Res. 2013;4:1622-7.

9. Ramirez-Avila LMDM, Noubary FP, Pansegrouw $D$, et al. The acceptability and feasibility of routine pediatric HIV testing in an outpatient clinic in Durban, South Africa. Pediatr Infect Dis J. 2013;32:1348-53. https://doi.org/10.1097/INF.0b013e31829ba34b
10. John-Stewart GC, Wariua G, Beima-Sofie KM, et al. Prevalence, perceptions, and correlates of pediatric HIV disclosure in an HIV treatment program in Kenya. AIDS Care 2013;25:1067-76. https://doi. org/10.1080/09540121.2012.749333

11. Vreeman RC, Gramelspacher AM, Gisore PO, et al. Disclosure of HIV status to children in resource-limited settings: a systematic review. J Int AIDS Soc. 2013;16:18466.

12. Turissini ML, Nyandiko WM, Ayaya SO, et al. The prevalence of disclosure of HIV status to HIV-infected children in western Kenya. J Pediatric Infect Dis Soc. 2013;2:136-43. https://doi.org/10.1093/ jpids/pit024

13. Alemu A, Berhanu B, Emishaw S. Challenges of caregivers to disclose their children S HIV positive status receiving highly active anti retroviral therapy at pediatric antiretroviral therapy clinics in Bahir Dar, North West Ethiopia. J AIDS HIV Res. 2013;2013.

14. Arrivé $E$, Dicko F, Amghar $H$, et al. HIV status disclosure and retention in care in HIV-infected adolescents on antiretroviral therapy (ART) in West Africa. PLoS One 2012;7.

15. Mweemba M, Musheke MM, Michelo $C$, et al. "When am I going to stop taking the drug?" Enablers, barriers and processes of disclosure of HIV status by caregivers to adolescents in a rural district in Zambia. BMC Public Health. 2015;15:1.

16. Mokgatle MM, Madiba S. The burden of disease on HIV-infected orphaned and non-orphaned children accessing primary health facilities in a rural district with poor resources in South Africa: a crosssectional survey of primary caregivers of HIV-infected children aged 5-18 years. Infect Dis Poverty. 2015;4:1-13.

17. De Schacht C, Lucas C, Mboa C, et al. Access to HIV prevention and care for HIV-exposed and HIV-infected children: a qualitative study in rural and urban Mozambique. BMC Public Health. 2014;14:1.

18. Lorenz R, Grant E, Muyindike W, et al. Caregivers' attitudes towards HIV testing and disclosure of HIV status to at-risk children in rural Uganda. PLoS One 2016;11:e0148950. https://doi.org/10.1371/ journal.pone. 0148950

19. Nzota MS, Matovu JK, Draper HR, et al. Determinants and processes of HIV status disclosure to HIV - infected children aged 4 to 17 years receiving HIV care services at Baylor College of Medicine Children's Foundation Tanzania, Centre of Excellence (COE) in Mbeya: a crosssectional study. BMC Pediatr. 2015;15:S85. https://doi.org/10.1186/ s12887-015-0399-3

20. Tadesse BT, Foster BA, Berhan Y. Cross sectional characterization of factors associated with pediatric HIV status disclosure in southern Ethiopia. PLoS One 2015;10:e0132691. https://doi.org/10.1371/ journal.pone. 0132691

21. Mahloko JM, Madiba S. Disclosing HIV diagnosis to children in Odi district, South Africa: reasons for disclosure and non-disclosure: original research. Afr. J. Prim. Health Care. Afr J Prim Health Care Fam Med. 2012;4:1-7.

22. Kiwanuka J, Mulogo E, Haberer JE. Caregiver perceptions and motivation for disclosing or concealing the diagnosis of HIV infection to children receiving HIV care in Mbarara, Uganda: a qualitative study. PLoS One 2014;9:e93276. https://doi.org/10.1371/journal. pone. 0093276

23. Madiba S and Mokwena K. Caregivers' barriers to disclosing the HIV diagnosis to infected children on antiretroviral therapy in a resourcelimited district in South Africa: a grounded theory study. AIDS Res Treat. 2012;2012.

24. Madiba S. Patterns of HIV diagnosis disclosure to infected children and family members: data from a paediatric antiretroviral program in South Africa. World J AIDS. 2012;2:212. https://doi.org/10.4236/ wja.2012.23027

25. Atwiine B, Kiwanuka J, Musinguzi N, et al. Understanding the role of age in HIV disclosure rates and patterns for HIV-infected children in southwestern Uganda. AIDS Care. 2015;27:424-30. https://doi.org/10 $.1080 / 09540121.2014 .978735$

26. Gyamfi E, Okyere P, Appiah-Brempong E, et al. Benefits of disclosure of HIV status to infected children and adolescents: perceptions of caregivers and health care providers. J Assoc Nurses AIDS Care. 2015;26:770-80. https://doi.org/10.1016/j.jana.2015.08.001 
27. Heeren GA, Jemmott III JB, Sidloyi L, et al. Disclosure of HIV diagnosis to HIV-infected children in South Africa: focus groups for intervention development. Vulnerable Child Youth Stud. 2012;7:47-54. https://doi. org/10.1080/17450128.2012.656733

28. Madiba S. Disclosing HIV to infected children in South Africa in the era of HAART: A grounded theory study on the process, reasons and outcomes of disclosure. WJA. 2012;2:319-29.
29. Madiba S, Mokgatle M. Health care workers' perspectives about disclosure to HIV-infected children; cross-sectional survey of health facilities in Gauteng and Mpumalanga provinces, South Africa. Peer J. 2015;3:e893.

30. Kajubi P, Whyte S, Muhumuza S, et al. Communication between HIVinfected children and their caregivers about HIV medicines: a crosssectional study in Jinja district, Uganda. J Int AIDS Soc. 2014;17:19012.

Received: 01-12-2016 Accepted: 01-05-2017 